\title{
Incubation of ovine scrapie with environmental matrix results in biological and biochemical changes of $\mathrm{PrP}^{\mathrm{SC}}$ over time
}

\author{
Ben C Maddison ${ }^{1}$, John Spiropoulos ${ }^{2}$, Christopher M Vickery², Richard Lockey ${ }^{2,3}$, Jonathan P Owen ${ }^{1}$, Keith Bishop ${ }^{1}$, \\ Claire A Baker ${ }^{1}$ and Kevin C Gough ${ }^{4^{*}}$
}

\begin{abstract}
Ovine scrapie can be transmitted via environmental reservoirs. A pool of ovine scrapie isolates were incubated on soil for one day or thirteen months and eluted prion was used to challenge tg338 mice transgenic for ovine PrP. After one-day incubation on soil, two PrPSc phenotypes were present: $G_{338}$ or Apl 338 ii. Thirteen months later some divergent PrP $P^{S c}$ phenotypes were seen: a mixture of $A_{p l} l_{338}$ ii with either $G_{338}$ or $P_{338}$, and a completely novel $\operatorname{PrP} P^{S c}$ deposition, designated $\mathrm{Cag}_{338}$. The data show that prolonged ageing of scrapie prions within an environmental matrix may result in changes in the dominant $\mathrm{PrP}^{\mathrm{Sc}}$ biological/biochemical properties.
\end{abstract}

\section{Introduction, methods and results}

Prion diseases (or transmissible spongiform encephalopathies, TSEs) are fatal, progressive neurological disorders that have no effective treatment or cure. Prion diseases include human Creutzfeldt-Jakob disease (CJD), bovine spongiform encephalopathy (BSE), scrapie in sheep and goats, and chronic wasting disease (CWD) in deer and elk. The prion hypothesis states that the causal agent is a misfolded version of the cellular prion protein $\left(\mathrm{PrP}^{\mathrm{C}}\right)$, termed $\operatorname{PrP}^{\mathrm{Sc}}[1]$.

It is known that particular prion diseases can include strains that display distinct and reproducible disease phenotypes. It is most likely that the prion agent is not a single entity but is made up of a plethora of different conformers of $\operatorname{PrP}^{\mathrm{Sc}}$ and the dominant $\operatorname{PrP}^{\mathrm{Sc}}$ conformation causes the specific disease characteristics for a particular infection including pathology, clinical signs and $\mathrm{PrP}^{\mathrm{Sc}}$ molecular signatures [2]. The identification of prion strains is in fact therefore a description of the dominant disease characteristics. The "gold standard" method employed to define scrapie strains is mouse bioassay using either wild type or preferably transgenic mice such as the $\operatorname{tg} 338$ line [3]. These transgenic mice

\footnotetext{
* Correspondence: kevin.gough@nottingham.ac.uk

${ }^{4} \mathrm{~S} c h$ ool of Veterinary Medicine and Science, The University of Nottingham Sutton Bonington Campus, College Road, Sutton Bonington, Leicestershire, UK Full list of author information is available at the end of the article
}

overexpress an ovine PrP transgene and display high sensitivity and specificity to ovine scrapie prions. Of the several phenotypic parameters exhibited in a host species which are used to discriminate TSEs, $\mathrm{PrP}^{\mathrm{Sc}}$ distribution in the brain detected by immunohistochemistry (IHC) or PET/Histo-blot offers the highest discriminatory power and it can be applied on an individual mouse basis [4-8]. This biological property of prions in conjunction with analysis of the biochemical properties of the agent recovered from the same host species offer a powerful means to identify TSE strains even when they are applied at primary passage as they remain essentially unchanged through serial passages $[4,6,9,10]$.

Scrapie is effectively transmitted between susceptible sheep and goats by animal-to-animal contact and via environmental reservoirs, a disease trait that is shared with CWD in deer/elk. For both diseases, the agent is disseminated widely in vivo and excreted/secreted via multiple routes (reviewed in [11]). The likely location of environmental reservoirs are water, soil, metal surfaces, wood surfaces and concrete surfaces $([12,13]$ reviewed in [14]). Furthermore, environmental prion is stable and remains infectious for years [15].

The purpose of the present study was to assess the viability of scrapie prions in a soil matrix over time. Pools of hindbrain from nine scrapie-infected sheep with VRQ/VRQ (amino acid positions 136, 156 and 171 
respectively) PRNP genotypes and twenty genotype matched scrapie-free controls were made into homogenates and applied to soil columns containing a sandy loam soil as previously described [16]. Soil columns were kept at $16-20{ }^{\circ} \mathrm{C}$ and constant water content and sampled 1 day and 13 months after the addition of the prion sample. Equivalent samples were taken for soil incubated with the prion-free control sample, and soil unexposed to brain material was used as a further control. All soil was removed from a column and homogenised by mixing. Prion protein was then extracted from soil [15]: $100 \mathrm{mg}$ of soil was re-suspended for $1 \mathrm{~h}$ in $500 \mu \mathrm{L}$ PBS prior to centrifugation at $800 \mathrm{~g}$ for $10 \mathrm{~min}$. The soil pellet was re-suspended in $100 \mu \mathrm{L}$ of $1 \%(\mathrm{w} / \mathrm{v})$ SDS in PBS and shaken vigorously for $1 \mathrm{~h}$. After centrifugation at $800 \mathrm{~g}$ for $10 \mathrm{~min}$ prion protein in the supernatant was removed. Extracted prion was then precipitated for $30 \mathrm{~min}$ at $37{ }^{\circ} \mathrm{C}$ by the addition of $15 \mu \mathrm{L}$ of $4 \%$ (w/v) sodium phosphotungstic acid (Napta) and $170 \mathrm{mM}$ magnesium chloride, and recovered by centrifugation at 12 $100 \mathrm{~g}$ for $30 \mathrm{~min}$. The pellet was air-dried and resuspended in $20 \mu \mathrm{L}$ sterile saline. Each inoculum $(20 \mu \mathrm{L})$ was used to challenge intracranially 5-10 week old $\operatorname{tg} 338$ mice $(n=10)$ as described previously [9]. After inoculation the mice were monitored for signs of neurological disease and were euthanized after exhibiting clinical signs. All animal work was approved by the Animal and Plant Health Agency local ethics committee and was carried out in accordance with the Animals (Scientific Procedures) Act 1986 under Home Office project license 70/6310. In combination with clinical signs, immunohistochemical (IHC) analysis was used to diagnose prion infection for all mice in the study. After euthanasia the brain of each mouse was removed and processed as described previously [9]. TSE diagnosis was based on $\mathrm{PrP}^{\mathrm{Sc}}$ detection in brain sections with polyclonal antibody Rb486 following a standard protocol [17]. Identification of different $\operatorname{PrP}^{\mathrm{Sc}}$ types and their distribution in the murine brain was used to identify defined $\mathrm{PrP}^{\mathrm{Sc}}$ distribution patterns as described previously for wild type and transgenic mice [4-7]. Slides were analysed blind by two independent observers (J.S. and C.V.); the agreement between the two observers regarding $\mathrm{PrP}^{\mathrm{Sc}}$ deposition pattern identification was $100 \%$.

With inoculum extracted from soil incubated with the scrapie sample for 1 day, eight out of the 10 challenged mice succumbed to TSE with incubation periods $<170$ days post inoculation (dpi) (Figure 1A). IHC analysis of the mice revealed granular $\mathrm{PrP}^{\mathrm{Sc}}$ deposits distributed mainly along the brainstem, thalamus and basal ganglia with little involvement of the cerebral or cerebellar cortex; this pattern has been previously designated as $\mathrm{G}_{338}$ (Figure 2A) [4]. One further mouse died $483 \mathrm{dpi}$ (Figure 1A) and the main $\mathrm{PrP}^{\mathrm{Sc}}$ pattern feature was plaques and large

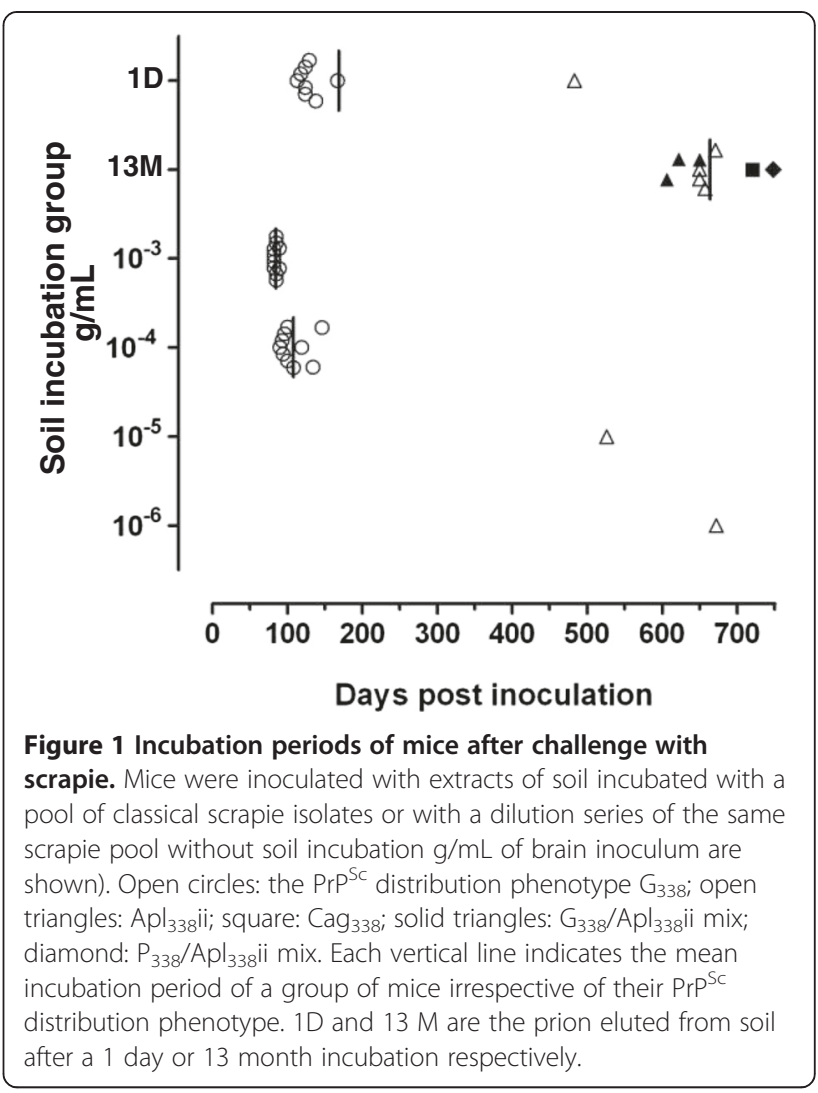

aggregates of $\operatorname{PrP}^{\mathrm{Sc}}$ in the brain parenchyma and perivascular plaques in round meningeal vessels (Figure $2 \mathrm{~B}$ ), a distribution pattern previously recorded as $\mathrm{Apl}_{338} \mathrm{ii}$. One mouse that died $243 \mathrm{dpi}$ was TSE negative and was treated as an intercurrent death. No mice displayed signs of TSE between 170-483 dpi.

After 13 months incubation of the scrapie sample on soil, prions were extracted and inoculated into tg338 mice. One mouse was diagnosed TSE negative (intercurrent death) and the remaining nine were TSE positive. The incubation period of the TSE positive mice was 606-748 dpi (Figure 1A). With one exception all mice showed a pattern that was compatible with $\mathrm{Apl}_{338}$ ii. This was the only pattern observed in four mice, while in another three it was observed in conjunction with $\mathrm{G}_{338}$ (Figures $2 \mathrm{D}-\mathrm{F}$ ) and in a single mouse signs of $\mathrm{Apl}_{338} \mathrm{ii}$ and $\mathrm{P}_{338}$ were observed concomitantly (Figure $2 \mathrm{G}$ ). $\mathrm{P}_{338}$ is a pattern characterised by punctate deposits in the neuropil and prominent welldefined intraneuronal $\operatorname{PrP}^{\mathrm{Sc}}$ accumulations as described previously [4]. One mouse also showed a previously unrecognised $\mathrm{PrP}^{\mathrm{Sc}}$ pattern designated $\mathrm{Cag}_{338}$ characterised by granular $\mathrm{PrP}^{\mathrm{Sc}}$ deposits, which increased in intensity multifocally, to give rise to coalescing aggregates in the neuropil (Figure 2C). The areas affected more extensively were the midbrain and the medulla.

Previous studies have shown that the $\mathrm{P}_{338}$ IHC presentation of $\mathrm{PrP}^{\mathrm{Sc}}$ is accompanied by a relatively low 


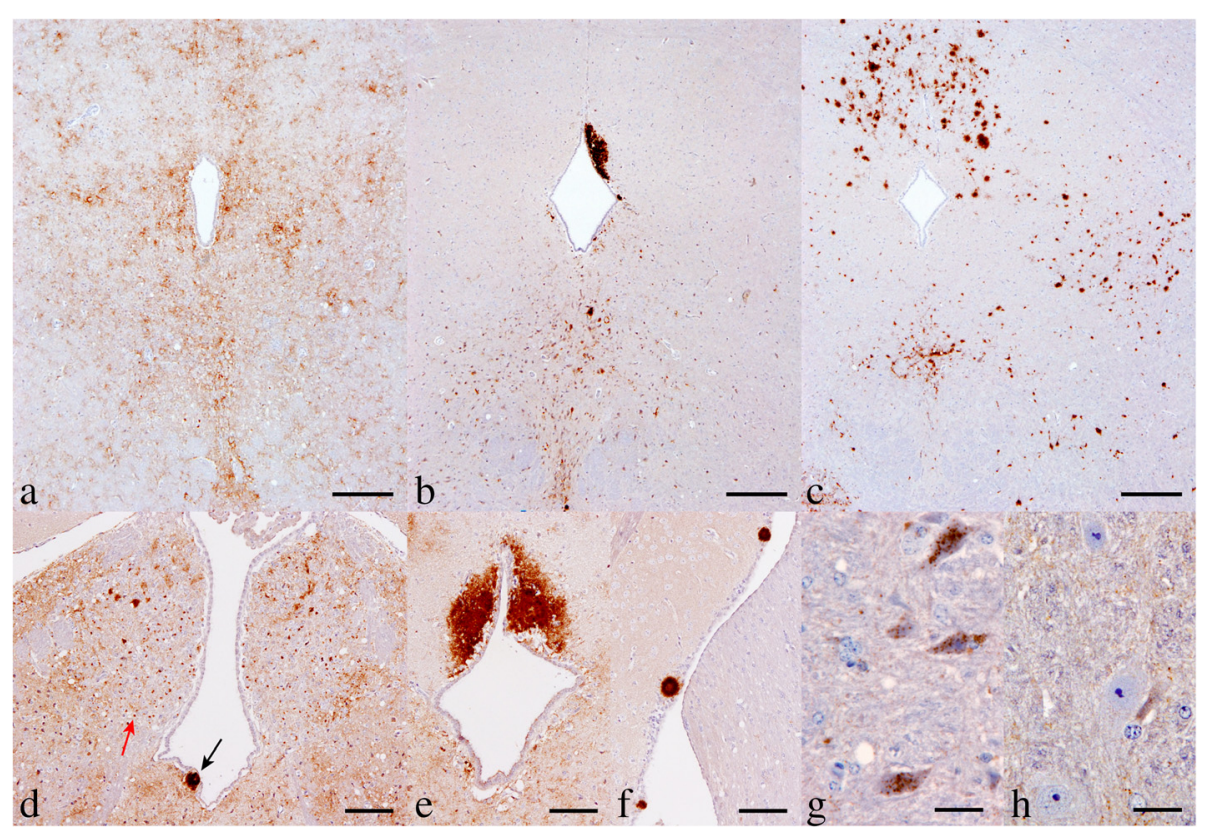

Figure 2 Representative images of $\mathrm{PrP}^{\mathrm{Sc}}$ deposition in the midbrain of $\operatorname{tg} 338$ mice after challenge with scrapie. The deposition patterns observed were characteristic of strains $\mathrm{G}_{338}$ (a), Apl $\mathrm{As}_{338} \mathrm{ii}$ (b) and $\mathrm{Cag}_{338}$ (c). Three mice showed phenotypic characteristics typical of both $\mathrm{G}_{338}$ and Apl $_{338}$ ii patterns; photos $d$-f are all from a single mouse showing small discrete aggregates (d, red arrow) in the habenular bodies which is a $G_{338}$ characteristic feature in addition to plaques and large aggregates in subpial areas (d, black arrow; e, periaqueductal grey matter; $\mathbf{f}$, lateral ventricle) which are associated with $\mathrm{Apl}_{338} \mathrm{ii}$. In a single mouse with $\mathrm{Apl}_{338}$ ii phenotype, punctate and prominent intraneuronal labelling (g) which are features associated with the $\mathrm{P}_{338}$ pattern were also observed; the $\mathrm{Apl}_{338} \mathrm{ii}$ phenotype is not usually associated with intraneuronal labelling (h). The neurons in $\mathbf{g}$ and $\mathbf{h}$ are located in the olive nucleus. Scale bar in a-c represents $250 \mu \mathrm{m} ; \mathbf{d}-\mathbf{f} 100 \mu \mathrm{m} ; \mathbf{g}$ and $\mathbf{h} 25 \mu \mathrm{m}$.

molecular weight for the PK-resistant $\operatorname{PrP}^{\mathrm{Sc}}$ compared to both $\mathrm{Apl}_{338} \mathrm{ii}$ and $\mathrm{G}_{338}[4,6]$. We looked to investigate whether the distinct IHC presentations described here were accompanied by distinct $\mathrm{PrP}^{\mathrm{Sc}}$ properties. Both the original sheep samples and the murine samples were digested with PK, analyzed on western blots and the prion detected with the antibody $\mathrm{SHa} 31$ as previously described [18] (Figures 3A and B). The results show that all ovine samples had indistinguishable $\operatorname{PrP}^{\mathrm{Sc}}$ profiles with an unglycosylated $\operatorname{PrP}^{\mathrm{Sc}}$ size of $19.0+/-0.3 \mathrm{kDa}$. The $\mathrm{G}_{338}, \mathrm{Apl}_{338} \mathrm{ii}$ and $\mathrm{G}_{338} / \mathrm{Apl}_{338} \mathrm{ii}$ mixed IHC phenotypes had a similar size of $19.1+/-0.3 \mathrm{kDa}$. However, the $\mathrm{Apl}_{338} \mathrm{ii} / \mathrm{P}_{338}$ mixed phenotype had a relatively low molecular mass by comparison of $17.1 \mathrm{kDa}$, consistent with previously published data for $\mathrm{P}_{338}[4,6]$. Also, the unglycosylated $\mathrm{PrP}^{\mathrm{Sc}}$ of $\mathrm{Cag}_{338}$ had a relatively high molecular mass of $20.6 \mathrm{kDa}$ (Figure 3B). In addition, we determined that the $\mathrm{G}_{338}$ and $\mathrm{Apl}_{338} \mathrm{ii}$ IHC phenotypes could be readily distinguished by the stability of their $\mathrm{PrP}^{\mathrm{Sc}}$ (Figures $3 \mathrm{C}$ and $\mathrm{D}$ ). The assay was carried out as described previously [19]. Briefly, aliquots of each murine brain homogenate were incubated with increasing molar concentrations of $\mathrm{GdnHCl}$ (final concentrations of $0.5,2.5,3.0,3.5$, and $4 \mathrm{M}) 1 \mathrm{~h}$ at $37^{\circ} \mathrm{C}$. Subsequently all samples were adjusted to a final $\mathrm{GdnHCl}$ concentration of $0.4 \mathrm{M}$, proteinase $\mathrm{K}$ was added to a final concentration of $50 \mu \mathrm{g} / \mathrm{mL}$ and the samples incubated for $1 \mathrm{~h}$ at $37^{\circ} \mathrm{C}$. Reactions were stopped with $5 \mathrm{mM}$ PMSF. Samples were analysed by western blot using antibody SHa31. The level of signal for each PrP triplet treated with $2.5,3.0,3.5$ or $4 \mathrm{M} \mathrm{GdnHCl}$ was expressed as a percentage of the signal for the same sample treated with $0.5 \mathrm{M} . \mathrm{G}_{338}$ was more susceptible to $\mathrm{GdnHCl}$ treatment becoming PK sensitive after treatment with $3 \mathrm{M}$ of the denaturant. In contrast, $\mathrm{Apl}_{338} \mathrm{ii}$ was relatively stable to denaturation with readily detectable PK-resistant $\mathrm{PrP}^{\mathrm{Sc}}$ after treatment with $4 \mathrm{M} \mathrm{GdnHCl}$ (Figures $3 \mathrm{C}$ and D). Overall, the $\operatorname{PrP}^{\mathrm{Sc}}$ biochemical characteristics were distinct for each of $\mathrm{Apl}_{338} \mathrm{ii}, \mathrm{G}_{338}, \mathrm{Apl}_{338} \mathrm{ii} / \mathrm{P}_{338}$ mixed and $\mathrm{Cag}_{338}$ IHC phenotypes.

Extracts from soil unexposed to brain material and soil treated with scrapie-free brain homogenate were bioassayed in tg338 mice and were TSE negative.

For comparison, the original scrapie sample without any incubation with soil was also titrated in tg338 mice over a range of 10 -fold dilutions $(n=10$ mice for each dilution; Figure 1B). All mice challenged with $20 \mu \mathrm{g}$ and $2 \mu \mathrm{g}$ scrapie brain succumbed to scrapie with a $\mathrm{G}_{338}$ IHC phenotype. Only one of the 10 mice challenged with either 200 or $20 \mathrm{ng}$ of brain pool was diagnosed with scrapie and in each case this produced an $\mathrm{Apl}_{338} \mathrm{ii}$ IHC phenotype. Challenge with lower amounts of brain 
a

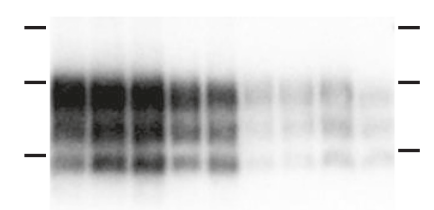

$\begin{array}{llllllllll}1 & 2 & 3 & 4 & 5 & 6 & 7 & 8 & 9\end{array}$

$\mathrm{C}$

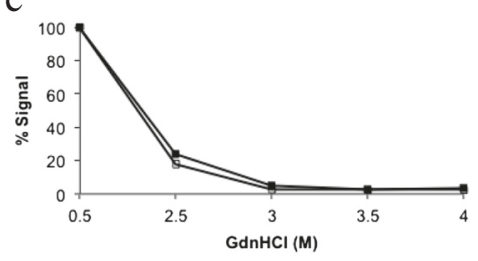

$\mathrm{b}$

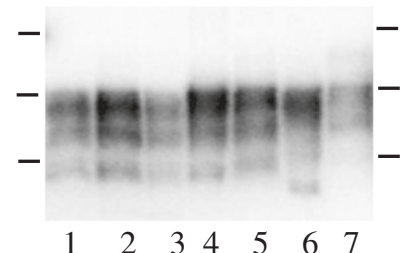

d

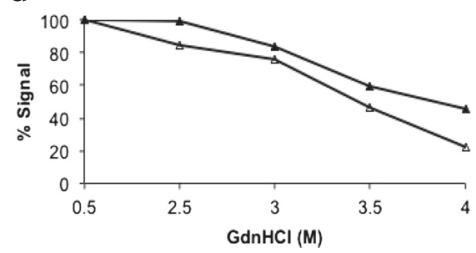

Figure $3 \mathrm{PrP}^{\mathrm{Sc}}$ characteristics of the scrapie isolates. Nine ovine hindbrain samples that were pooled and incubated with soil (a) were analysed by western blot. Murine isolates (b) designated $G_{338}$ (lanes 1, 2 and 3), Apl $\left.\right|_{338}$ ii (lane 4), Apl 338 ii/ $G_{338}$ mixed phenotype (lane 5), Apl 338 ii/ $\mathrm{P}_{338}$ mixed phenotype (Lane 6) and $\mathrm{Cag}_{338}$ (Lane 7) are also shown. Blots were probed with anti-PrP antibody SHa31 and molecular mass markers of 20, 30 and $40 \mathrm{kDa}$ are indicated. All samples were analysed twice to determine the molecular mass of unglycosylated PrPSc and gave consistent results. The strains $\mathrm{G}_{338}$ (c) and $\mathrm{Apl}_{338}$ ii (d) were further analysed by the conformational stability assay and gave distinct profiles. These molecular traits were consistent both before (closed symbols) and after (open symbols) treatment with SDS and Napta. Analysis was carried out on 3 murine isolates of $\mathrm{G}_{338}$ and 2 murine isolates of $\mathrm{Apl}_{338} \mathrm{il}$ and the presented data is representative of these isolates.

pool did not cause disease. Prion desorbed from soil after 1 day displayed the same $\mathrm{IHC}$ and $\mathrm{PrP}^{\mathrm{Sc}}$ phenotypes as the original scrapie pool, that is $\mathrm{Apl}_{338} \mathrm{ii}$ and $\mathrm{G}_{338}$. However, it is possible that the extraction and precipitation treatments have an effect on $\operatorname{PrP}^{\mathrm{Sc}}$ phenotype or recovery. To test this, murine brain homogenates for $\mathrm{G}_{338}$ and $\mathrm{Apl}_{338} \mathrm{ii}$ phenotypes $(10 \% \mathrm{w} / \mathrm{v} ; 100 \mu \mathrm{L})$ were diluted to $200 \mu \mathrm{L}$ with $2 \%$ (w/v) SDS and shaken vigorously for $1 \mathrm{~h}$. After centrifugation at $800 \mathrm{~g}$ for $10 \mathrm{~min}$ prion in the supernatant was precipitated with Napta and brain homogenate and Napta precipitate were analyzed by western blot as detailed above and the total signal for the PrP triplet was determined by densitometry. The percentage recovery after SDS treatment/Napta precipitation for each isolate was determined and comparison of the recoveries of $\mathrm{G}_{338}$ and $\mathrm{Apl}_{338} \mathrm{ii}$ was carried out using a two-tailed students $t$-test. The percentage recoveries for 3 isolates of murine $G_{338}$ and 2 isolates of murine $\mathrm{Apl}_{338} \mathrm{ii}$ were determined and the mean recoveries were 57 and 56\% respectively, differences in the recoveries of the two $\operatorname{PrP}^{\mathrm{Sc}}$ phenotypes were not significant $(p=0.97)$. In addition, the molecular phenotypes were maintained before and after SDS/Napta treatment (Figures $3 \mathrm{C}$ and D).

\section{Discussion}

The bioassay data show that the hit rate was equivalent for sheep scrapie extracted from soil after 1 day or 13 months incubation indicating ovine scrapie infection was retained on soil over a prolonged time period. The data also clearly suggest that between day 1 and month 13 the biological and biochemical properties of the prion that is desorbed from soil change considerably. In our view, this concomitant change of biological and biochemical properties as described here is indicative of strain variation. Indeed many of these phenotypic characteristics have been attributed to characterised strains isolated and studied in tg338 mice (Table 1) $[4,6]$. Some

Table 1 Main features of characterised strains identified in this study [4,6]

\begin{tabular}{|c|c|c|c|}
\hline \multirow[b]{2}{*}{ Strain } & \multirow[b]{2}{*}{ Incubation period (IP)* } & \multicolumn{2}{|l|}{ Main PrP ${ }^{\mathrm{Sc}}$ characteristics } \\
\hline & & Immunohistochemistry (IHC) & Western blot ${ }^{\#}$ \\
\hline $\mathrm{G}_{338}$ & $78 \pm 6$ & Granular deposits mainly in brain stem and thalamus & $21 \mathrm{KDa}$ \\
\hline$P_{338}$ & $153 \pm 8$ & Punctate and intraneuronal deposits mainly in brain stem and thalamus & $19 \mathrm{KDa}$ \\
\hline $\mathrm{Apl}_{338} \mathrm{ii}$ & $249 \pm 59$ & Aggregates and plaques. Midbrain is most affected area & $21 \mathrm{KDa}$ \\
\hline
\end{tabular}

*Incubation period (IP) values denote mean \pm SD and indicate days post inoculation (dpi) after three serial passages. At first passage IP values of certain strains such as $\mathrm{Apl}_{338}$ may be prolonged [6]. $\mathrm{G}_{338}$ is an exceptional strain as shorter IP values can be observed at primary passage [21] with serial passages resulting in IP prolongation by approximately $12 \mathrm{dpi}$.

"Western blot values refer to the molecular mass of the unglycosylated band. Absolute values may differ depending on the western blot conditions. However, the $\mathrm{P}_{338}$ unglycosylated band always migrates further indicating a $2 \mathrm{KDa}$ lower molecular mass compared to $\mathrm{G}_{338}$ and $\mathrm{Apl}_{338} \mathrm{ii}$. 
of the strain phenotypes identified after a 13 month incubation are highly novel. Both $\mathrm{G}_{338}$ and $\mathrm{P}_{338}$ strains are relatively fast incubation strains and have not been reported before in a mixed phenotype with $\mathrm{Apl}_{338} \mathrm{ii}$ or at these prolonged incubation times. The identification particularly of $\mathrm{G}_{338}$ IHC characteristics, in conjunction with $\mathrm{Apl}_{338} \mathrm{ii}$, in the brains of mice showing incubation period $>600 \mathrm{dpi}$ is intriguing as the maximum incubation period associated with $\mathrm{G}_{338}$ is known to be $<200 \mathrm{dpi}$ [20]. Therefore the possibility that $\mathrm{G}_{338}$ was existing as an independent entity in the inoculum used to challenge the mice is unlikely even if we accept that in the presence of a significantly slower strain, such as $\mathrm{Apl}_{338} \mathrm{ii}$, the propagation of $\mathrm{G}_{338}$ was delayed. Another possible explanation would be that agents with $G_{338}$ or $P_{338}$ properties could emerge from $\mathrm{Apl}_{338} \mathrm{ii}$ at a later stage of the incubation period. Alternatively the $G_{338}$ and $P_{338}$ phenotypic characteristics that were observed in conjunction with $\mathrm{Apl}_{338} \mathrm{ii}$ indicate phenotypes that have some $\mathrm{G}_{338}$ or $\mathrm{P}_{338}$ properties associated with unusually prolonged incubation periods. Without isolating each of these agents in a pure state to study their properties it is not possible to draw definitive conclusions regarding their exact strain characteristics. However, their existence at this stage, particularly of the $\mathrm{P}_{338} \mathrm{IHC}$ phenotype, which is also accompanied with biochemical properties that are attributed to the $\mathrm{P}_{338}$ strain, cannot be ignored and adds valuable information regarding the diversity of scrapie phenotypes that can emerge after prolonged incubation period with soil. The $\mathrm{Cag}_{338}$ strain phenotype is reported here for the first time. Collectively, therefore, these data suggest that the ageing of prions within an environmental matrix can affect their biological and biochemical properties suggesting strain alterations. The three novel phenotypes of desorbed prion strains observed after 13 months incubation on soil were not detected in a range of 10-fold dilutions of the original scrapie sample and the SDS/Napta treatment of samples to desorb them from soil had no apparent effect on $G_{338}$ or $\mathrm{Apl}_{338} \mathrm{ii}$ recovery or $\mathrm{PrP}^{\mathrm{Sc}}$ phenotype. Therefore, these novel $\mathrm{PrP}^{\mathrm{Sc}}$ presentations must be a consequence of their interaction with soil or ageing or both. It is not known whether this emergence of novel phenotypes seen here during ageing on soil reflects the selection of existing conformers present in the original sample or de novo mutation to produce novel conformations of the prion. The study compared $\operatorname{PrP}^{\mathrm{Sc}}$ phenotypes that are recovered from soil after 1 day and 13 month periods and the effects of soil interaction and incubation time alone are not considered separately. Therefore it is also not known whether the observed changes in dominant prion strains are dictated by incubation time at ambient temperature alone or by interaction with soil over a prolonged period. However, regardless of the mechanisms of the observed ageing, the unequivocal finding is that when a mixture of prion phenotypes are added to a soil environment the dominant pathologies change over time. Whether analogous ageing of prions occurs in other natural environments that may harbour prion reservoirs remains to be established. The presence of "dynamic" reservoirs of environmental scrapie infectivity could possibly lead to the emergence of novel strains of scrapie in natural infections. Such events may have contributed to the significant (and unusual) diversity of the scrapie disease agent.

\section{Abbreviations}

TSE: Transmissible spongiform encephalopathy; CWD: Chronic wasting disease; $\operatorname{PrP} / \operatorname{PrPC}$ : Cellular prion protein; $\mathrm{PrP}^{\mathrm{SC}}$ : Disease-associated prion protein; IHC: Immunohistochemistry; Napta: Sodium phosphotungstic acid.

\section{Competing interests}

The authors declare that they have no competing interests.

\section{Authors' contributions}

KCG and BCM conceived this study and participated in its design and coordination. JS, RL and CMV carried out the bioassay JS and CMV conducted $\mathrm{IHC}$ analysis of the samples and the interpretation of the findings. $\mathrm{JO}, \mathrm{KB}$ and $\mathrm{CB}$ carried out the soil experiments and prepared the inoculums, analysed samples by western blot and conformational stability assay. KCG and BCM have written the manuscript with inputs from all authors. All authors read and approved the final manuscript.

\section{Acknowledgements}

This work was supported by the Department for Environment, Food and Rural Affairs, UK (Defra project SE1858). The authors would like to thank colleagues in Pathology and Animal Science Unit at APHA for their skilled technical expertise and support. We thank the Biological-archive, APHA (Addlestone, Surrey, UK) for the provision of sheep brain material.

\section{Author details}

${ }^{1}$ ADAS UK, School of Veterinary Medicine and Science, The University of Nottingham, Sutton Bonington Campus, College Road, Sutton Bonington, Leicestershire, UK. ${ }^{2}$ Animal and Plant Health Agency, Woodham Lane, New Haw, Addlestone, Surrey, UK. ${ }^{3}$ Current address: University of Southampton, Southampton SO17 1BJ, UK. ${ }^{4}$ School of Veterinary Medicine and Science, The University of Nottingham, Sutton Bonington Campus, College Road, Sutton Bonington, Leicestershire, UK.

Received: 25 November 2014 Accepted: 2 April 2015

Published online: 01 May 2015

\section{References}

1. Prusiner SB (1998) Prions. Proc Natl Acad Sci U S A 95:13363-13383

2. Collinge J, Clarke AR (2007) A general model of prion strains and their pathogenicity. Science 318:930-936

3. Vilotte JL, Soulier S, Essalmani R, Stinnakre MG, Vaiman D, Lepourry L, Da Silva JC, Besnard N, Dawson M, Buschmann A, Groschup M, Petit S, Madelaine MF, Rakatobe S, Le Dur A, Vilette D, Laude H (2001) Markedly increased susceptibility to natural sheep scrapie of transgenic mice expressing ovine PrP. J Virol 75:5977-5984

4. Thackray AM, Hopkins L, Lockey R, Spiropoulos J, Bujdoso R (2011) Emergence of multiple prion strains from single isolates of ovine scrapie. J Gen Virol 92:1482-1491

5. Beck KE, Vickery CM, Lockey R, Holder T, Thorne L, Terry LA, Denyer M, Webb P, Simmons MM, Spiropoulos J (2012) The interpretation of disease phenotypes to identify TSE strains following murine bioassay: characterisation of classical scrapie. Vet Res 43:77

6. Thackray AM, Hopkins L, Lockey R, Spiropoulos J, Bujdoso R (2012) Propagation of ovine prions from "poor" transmitter scrapie isolates in ovine PrP transgenic mice. Exp Mol Pathol 92:167-174

7. Beck KE, Sallis RE, Lockey R, Vickery CM, Beringue V, Laude H, Holder TM, Thorne L, Terry LA, Tout AC, Jayasena D, Griffiths PC, Cawthraw S, Ellis R, Balkema-Buschmann A, Groschup MH, Simmons MM, Spiropoulos J (2012) Use of murine bioassay to resolve ovine transmissible spongiform 
encephalopathy cases showing a bovine spongiform encephalopathy molecular profile. Brain Pathol 22:265-279

8. van Keulen $\sqcup$, Langeveld JP, Dolstra CH, Jacobs J, Bossers A, van Zijderveld FG: TSE strain differentiation in mice by immunohistochemical PrP profiles and triplex Western blot. Neuropathol Appl Neurobiol, in press

9. Corda E, Beck KE, Sallis RE, Vickery CM, Denyer M, Webb PR, Bellworthy SJ, Spencer Yl, Simmons MM, Spiropoulos J (2012) The interpretation of disease phenotypes to identify TSE strains in mice: characterisation of BSE using $\operatorname{PrP}^{\mathrm{SC}}$ distribution patterns in the brain. Vet Res 43:86

10. Le Dur A, Beringue V, Andreoletti O, Reine F, Lai TL, Baron T, Bratberg B, Vilotte J-L, Sarradin P, Benestad SL, Laude H (2005) A newly identified type of scrapie agent can naturally infect sheep with resistant PrP genotypes. Proc Natl Acad Sci U S A 102:16031-16036

11. Gough KC, Maddison BC (2010) Prion transmission: prion excretion and occurrence in the environment. Prion 4:275-282

12. Maddison BC, Baker CA, Terry LA, Bellworthy SJ, Thorne L, Rees HC, Gough KC (2010) Environmental sources of scrapie prions. J Virol 84:11560-11562

13. Nichols TA, Pulford B, Wyckoff AC, Meyerett C, Michel B, Gertig K, Hoover EA, Jewell JE, Telling GC, Zabel MD (2009) Detection of protease-resistant cervid prion protein in water from a CWD-endemic area. Prion 3:171-183

14. Bartelt-Hunt SL, Bartz JC (2013) Behavior of prions in the environment: implications for prion biology. PLoS Pathog 9:e1003113

15. Seidel B, Thomzig A, Buschmann A, Groschup MH, Peters R, Beekes M, Terytze K (2007) Scrapie agent (strain 263 k) can transmit disease via the oral route after persistence in soil over years. PLoS One 2:e435

16. Maddison BC, Owen JP, Bishop K, Shaw G, Rees HC, Gough KC (2010) The interaction of ruminant $\operatorname{PrP}^{\mathrm{Sc}}$ with soils is influenced by prion source and soil type. Environ Sci Technol 44:8503-8508

17. Vickery CM, Beck KE, Simmons MM, Hawkins SA, Spiropoulos J (2013) Disease characteristics of bovine spongiform encephalopathy following inoculation into mice via three different routes. Int J Exp Pathol 94:320-328

18. Owen JP, Maddison BC, Whitelam GC, Gough KC (2007) Use of thermolysin in the diagnosis of prion diseases. Mol Biotechnol 35:161-170

19. Peretz D, Scott MR, Groth D, Williamson RA, Burton DR, Cohen FE, Prusiner SB (2001) Strain-specified relative conformational stability of the scrapie prion protein. Protein Sci 10:854-863

20. Andréoletti $O$, Orge L, Benestad SL, Beringue $V$, Litaise C, Simon S, Le Dur A, Laude $\mathrm{H}$, Simmons H, Lugan S, Corbière F, Costes P, Morel N, Schelcher S, Lacroux C (2011) Atypical/Nor98 Scrapie Infectivity in Sheep Peripheral Tissues. PLoS Pathog 7:e1001285

21. Thackray AM, Hopkins L, Spiropoulos J, Budjoso R (2008) Molecular and transmission characteristics of primary-passaged ovine scrapie isolates in conventional and transgenic mice. J Virol 82:11197-11207

\section{Submit your next manuscript to BioMed Central and take full advantage of:}

- Convenient online submission

- Thorough peer review

- No space constraints or color figure charges

- Immediate publication on acceptance

- Inclusion in PubMed, CAS, Scopus and Google Scholar

- Research which is freely available for redistribution

Submit your manuscript at www.biomedcentral.com/submit 